Article

\title{
Preterm Birth and Small-for-Gestational Age Neonates among Prepregnancy Underweight Women: A Case-Controlled Study
}

\author{
Emelyne Lefizelier ${ }^{1}$, Emilie Misbert ${ }^{2}$, Marion Brooks ${ }^{1}$, Aurélie Le Thuaut ${ }^{3}$, Norbert Winer ${ }^{2}$ and \\ Guillaume Ducarme ${ }^{1, * \text { (D) }}$ \\ 1 Department of Obstetrics and Gynaecology, Centre Hospitalier Departemental, \\ 85000 La Roche sur Yon, France; emelyne.lefizelier@ght85.fr (E.L.); marion.brooks@ght85.fr (M.B.) \\ 2 Department of Obstetrics and Gynaecology, Nantes University Hospital, 44000 Nantes, France; \\ emilie.misbert@chu-nantes.fr (E.M.); norbert.winer@chu-nantes.fr (N.W.) \\ 3 Plateforme de Méthodologie et Biostatistique, CHU Nantes, 44093 Nantes, France; \\ aurelie.lethuaut@chu-nantes.fr \\ * Correspondence: g.ducarme@gmail.com; Tel.: +33-2514-46570; Fax: +33-2514-46404
}

check for updates

Citation: Lefizelier, E.; Misbert, E.; Brooks, M.; Le Thuaut, A.; Winer, N.; Ducarme, G. Preterm Birth and Small-for-Gestational Age Neonates among Prepregnancy Underweight Women: A Case-Controlled Study. J. Clin. Med. 2021, 10, 5733. https:// doi.org/10.3390/jcm10245733

Academic Editors: Simone Ferrero and Erich Cosmi

Received: 29 October 2021

Accepted: 3 December 2021

Published: 7 December 2021

Publisher's Note: MDPI stays neutral with regard to jurisdictional claims in published maps and institutional affiliations.

Copyright: (c) 2021 by the authors. Licensee MDPI, Basel, Switzerland. This article is an open access article distributed under the terms and conditions of the Creative Commons Attribution (CC BY) license (https:// creativecommons.org/licenses/by/ $4.0 /)$.

\begin{abstract}
The aim of our study was to investigate whether prepregnancy underweight body mass index (BMI) is associated with preterm birth (PTB) and small-for-gestational age (SGA). This retrospective case-control study included 814 women with live singleton fetuses in vertex presentation that gave birth between January 2016 and November 2016 in two tertiary care hospitals. The study group $(n=407)$ comprised all women whose prepregnancy BMI was underweight $\left(<18.5 \mathrm{~kg} / \mathrm{m}^{2}\right)$ and who delivered during the study period. A control group $(n=407)$ was established with women whose prepregnancy BMI was normal $\left(18.5-24.9 \mathrm{~kg} / \mathrm{m}^{2}\right)$ by matching age and parity. Univariate and multivariate analyses were performed to compare PTB and SGA associated with prepregnancy underweight BMI. Compared with the control group, the study group had higher rates of overall PTB (10.1\% vs. 5.7\%, $p=0.02)$, iatrogenic PTB (4.2\% vs. $1.5 \%, p=0.02)$, and SGA $(22.1 \%$ vs. $11.1 \%$, $p<0.001)$. In a multivariable analysis, prepregnancy underweight BMI was associated with PTB (aOR 2.32, 95\% CI 1.12-4.81) and with SGA (aOR 2.38, 95\% CI 1.58-3.58). In singleton pregnancies, women's prepregnancy underweight compared with normal BMI was associated with an increase in PTB and in SGA neonates. Identifying this specific high-risk group is pragmatic and practical for all physicians, and they should be aware about perinatal outcome among underweight women.
\end{abstract}

Keywords: pregnancy; preterm birth; underweight; small for gestational age

\section{Introduction}

Despite the current obesity epidemic, prepregnancy underweight, defined by the World Health Organization International Classification as a Body Mass Index (BMI) lower than $18.5 \mathrm{~kg} / \mathrm{m}^{2}$ [1], remains a common occurrence. Maternal underweight was reported among $7.5 \%$ of pregnant women $[2,3]$.The analysis of the literature on maternal and perinatal outcomes among underweight women shows discrepancies. In a large population-based cohort from California, no association was reported between underweight BMI and spontaneous preterm birth (PTB; $<37$ weeks' gestation), due to major influences by race/ethnicity, gestational age, and parity [4].Conversely, in a retrospective cohort in Colorado, underweight women were significantly more likely to have a PTB (adjusted odds ratio $2.4 ; 95 \%$ confidence interval (CI) 1.4-4.2; $p=0.003$ ) [5]. More recently, a meta-analysis, involving 78 studies, 1,025,794 women in developed and in developing countries, reported that prepregnancy underweight was significantly associated with PTB, compared to a normal prepregnancy BMI (adjusted relative risk (RR) 1.29, 95\% CI 1.15-1.46) [6]. In the most recent retrospective cohort study in California including 950,356 California deliveries in 2007-2010 with 72,686 (7.6\%) underweight women, increasing severity of prepregnancy underweight BMI was associated with increasing risk-adjusted PTB [3]. The meta-analysis 
also showed that underweight women had an increased risk of low-birth weight infant and small-for-gestational age (SGA), compared to a normal prepregnancy BMI (adjusted RR 1.64, 95\% CI 1.38-1.94) [6].

In a retrospective case-control study, we aimed to compare PTB and SGA for underweight and normal BMI women, and to analyse the risk factors for PTB and SGA in underweight women.

\section{Materials and Methods}

\subsection{Patient Selection}

This is a retrospective case-control study. The study group comprised all women with a prepregnancy underweight BMI $\left(<18.5 \mathrm{~kg} / \mathrm{m}^{2}\right)$, carrying a live singleton fetus in vertex presentation, who gave birth from January 2016 to November 2016 at two tertiary care hospitals. A control group of pregnant women who gave birth during the same study period with normal prepregnancy BMI $\left(18.5-24.9 \mathrm{~kg} / \mathrm{m}^{2}\right)$ was established by matching, one-to-one, according to maternal prepregnancy age (less than 20 years, between 20 and 39 years, and over 39 years), parity (nulliparous or multiparous), month of birth, and hospital. We excluded women without first-trimester ultrasound gestational age dating, multiple pregnancy, and women with medical-indicated second trimester termination of pregnancy, intra uterine death or fetal loss before 22 weeks.

This present study was conducted in accordance with the French approved guidelines. All participants received written information. Written consent was not required for retrospective study according to the French law, but each woman got the opportunity to opt out of the analysis. The study protocol was approved by a Research Ethics Committee (Groupe Nantais d'Ethique dans le Domaine de la Santé (GNED)) on 27 June 2017 before the beginning of the study.

\subsection{Data Collection}

Maternal demographic characteristics, information regarding pregnancy follow-up and standard perinatal outcomes were collected retrospectively by one obstetrician (E.L.) from the electronic medical record database of the two hospitals included in our study. Maternal characteristics collected included maternal prepregnancy age, BMI (calculated as weight $(\mathrm{kg}) /[\text { height }(\mathrm{m})]^{2}$ ), based on height and the first weight noted in the obstetric record), geographic origin (North Africa, Sub-Saharan Africa, Hispanic, Asian, Overseas departments, Caucasian), severity of maternal underweight BMI (severe (BMI, $<16 \mathrm{~kg} / \mathrm{m}^{2}$ ), moderate (BMI, $16-16.99 \mathrm{~kg} / \mathrm{m}^{2}$ ), and mild (BMI, 17-18.49 kg/m²)) [1], parity, smoking (defined by smoking regardless of the amount cigarettes smoked), previous uterine scar (previous caesarean section or myomectomy), previous hypertension [7], pregestational diabetes mellitus, history of depression, and history of eating behaviour disorders (anorexia or bulimia).

Pregnancy and labour characteristics collected included assisted reproductive technologyconceived pregnancy, gestational weight gain (GWG) [8], gestational diabetes mellitus (GDM), pregnancy-associated hypertensive disorders, anaemia (defined by haemoglobin $<11 \mathrm{~g} / \mathrm{dL}$ before delivery) [9], intrahepatic cholestasis of pregnancy (ICP), threatened preterm labour required hospitalization, and antenatal suspicion of SGA. Maternal gestational weight gain (GWG) was calculated as measured weight at the end of pregnancy minus pre-pregnancy weight. Adequate GWG was based on the Institute of Medicine's GWG by maternal pre-pregnancy BMI recommendations [8]. GDM was diagnosed as usual, according to international guidelines for pregnant women [10]. Women who were controlled with antenatal insulin therapy (AIT) were allowed to await spontaneous labour until 41 weeks. Women who were not controlled on diet alone or with AIT or who presented with an estimated foetal weight $>97$ th centile at 37 weeks were advised to undergo induction of labour at 39 weeks [11]. Pregnancy-associated hypertension disorders were determined by hypertension without proteinuria or preeclampsia (hypertension and proteinuria) after 20 weeks' gestation in a previously normotensive woman [12]. In case of 
non-severe preeclampsia beyond 36 weeks, elective delivery must be considered, and in case of severe preeclampsia beyond 34 weeks, elective delivery is indicated. Intrahepatic cholestasis of pregnancy is a cholestatic disorder characterized by pruritus with onset in the second or third trimester of pregnancy and elevated serum aminotransferases and bile acid levels. According to our institutional guidelines, women who were not clinically and/or biologically controlled with ursodeoxycholic acid were advised to undergo induction of labour at 37 weeks of gestation. Antenatal suspicion of SGA was defined as an ultrasonographic estimated foetal weight $<10$ th centile adjusting for gestational age and sex [13]. According to French guidelines, elective delivery was recommended between 30-32 weeks and 38-39 weeks of gestation according to estimated fetal weight (less than the 3rd percentile, or between the 3rd and 10th percentile) and umbilical artery Doppler waveform (normal/absent/reversed end-diastolic velocity) [14].

Intrapartum variables collected included gestational age at delivery [15], spontaneous or iatrogenic PTB (defined as delivery less than 37 completed weeks of gestation, but analytically defined more narrowly, less than 28 weeks, 28-32 weeks, or 32-36 weeks (compared with 37-41 weeks)), type of labour (spontaneous or induced, planned caesarean delivery), mode of delivery (spontaneous or operative vaginal delivery, or caesarean section during labour), third or fourth degree perineal tears [16], postpartum haemorrhage (PPH, defined as bleeding $500 \mathrm{~mL}$ or greater after vaginal delivery) and severe PPH (defined as bleeding $1000 \mathrm{~mL}$ or greater) [17], and birth weight (calculated in grams, centile and Z-score adjusting for gestational age and the offspring's sex) [18], Low-birth weight (LBW) neonate was defined as less than $2500 \mathrm{~g}$, and macrosomia was defined as greater than $4000 \mathrm{~g}$. SGA neonate was defined as birth weight less than the 10th percentile adjusting for gestational age and the offspring's sex, and large for gestational age (LGA) neonate as birth weight greater than the 90th percentile adjusting for gestational age and the offspring's sex [19].

In addition, we routinely measured newborns' umbilical arterial blood gases at birth. A paediatrician examined the newborn in all cases after delivery. Infants in need of close monitoring were transferred to the neonatal intensive care unit (NICU). Immediate neonatal morbidity data recorded were 5-min Apgar score, cord $\mathrm{pH}$, any transfer to the NICU, respiratory distress syndrome, neonatal hyperbilirubinemia, neonatal hypoglycaemia, intraventricular haemorrhage greater than grade 2, need for resuscitation or intubation, sepsis, seizures, and neonatal death. Respiratory distress syndrome was defined by the presence of respiratory distress, an increased oxygen requirement $\left(\mathrm{FiO}_{2} \geq 0.4\right)$ and compatible chest radiographic findings without any evidence of another cause of respiratory distress [20]. Neonatal hypoglycaemia was defined as blood glucose $<40 \mathrm{mg} / \mathrm{dL}$ in the first $24 \mathrm{~h}$ post-delivery or blood glucose $<50 \mathrm{mg} / \mathrm{dL}$ from the second day of life [21]. Neonatal hyperbilirubinemia was recorded when the infant was treated with phototherapy after birth or admission at the neonatology department for this reason. Neonatal sepsis was defined as confirmed clinical infection with positive bacteriological tests [22].

To calculate sample size, we assumed a maximum rate of PTB of $12 \%$ among underweight women $[3,6]$, and a minimum rate of PTB of $6 \%$ in women with a normal BMI $[3,6,23-25]$. For a power of $85 \%$ to detect a reduction in PTB from $12 \%$ to $6 \%$ between the two groups using a two-tailed t-test and alpha error of $0.05,814$ women (407 women per group) were required in the study.

\subsection{Statistical Analysis}

Continuous data were described by their means \pm standard deviations and compared by $t$ tests (or Mann-Whitney tests when appropriate), and categorical data were described by percentages and compared by $\chi^{2}$ tests (or Fisher's exact tests when appropriate). We compared maternal and perinatal outcomes according to BMI, and specifically studied the association (assessed by multivariate logistic regression analyses) between PTB and SGA with prepregnancy underweight BMI, compared with normal BMI. If the association between PTB and SGA and a maternal characteristic was a clinically relevant potential 
for confounding or was already known from the literature for being linked to PTB and to SGA $[3,6]$, the factor was added in the multivariable analyses. SAS 9.4 software (SAS Institute, Cary, NC, USA) was used was used for all analyses. $p$ values $<0.05$ were considered to be statistically significant.

\section{Results}

In the analytic dataset of 5931 live births during the study period, 407 women $(6.86 \%)$ presented prepregnancy underweight BMI. These women (study group) were compared to 407 matched women in a control group (Figure 1). Table 1 details the maternal and labour characteristics and maternal and neonatal outcomes. Smoking, history of depression and history of eating behaviour disorder were significantly more frequent in underweight women, $(30.0 \%$ compared to $19.9 \%, p=0.001 ; 6.9 \%$ compared to $3.0 \%, p=0.01$; and $6.1 \%$ compared to $2.5 \%, p=0.01$, respectively). GWG was significantly higher in study group (13.1 \pm 4.2 compared to $12.3 \pm 4.7 \mathrm{~kg}, p=0.02)$. Threatened preterm labour requiring hospitalization was twice as frequent in cases $(8.6 \%$ compared to $3.7 \%, p<0.01)$, and ICP was four-times as frequent in control group ( $0.5 \%$ compared to $2.2 \%, p=0.03)$. No difference was observed between groups regarding geographic origin (Table 1).

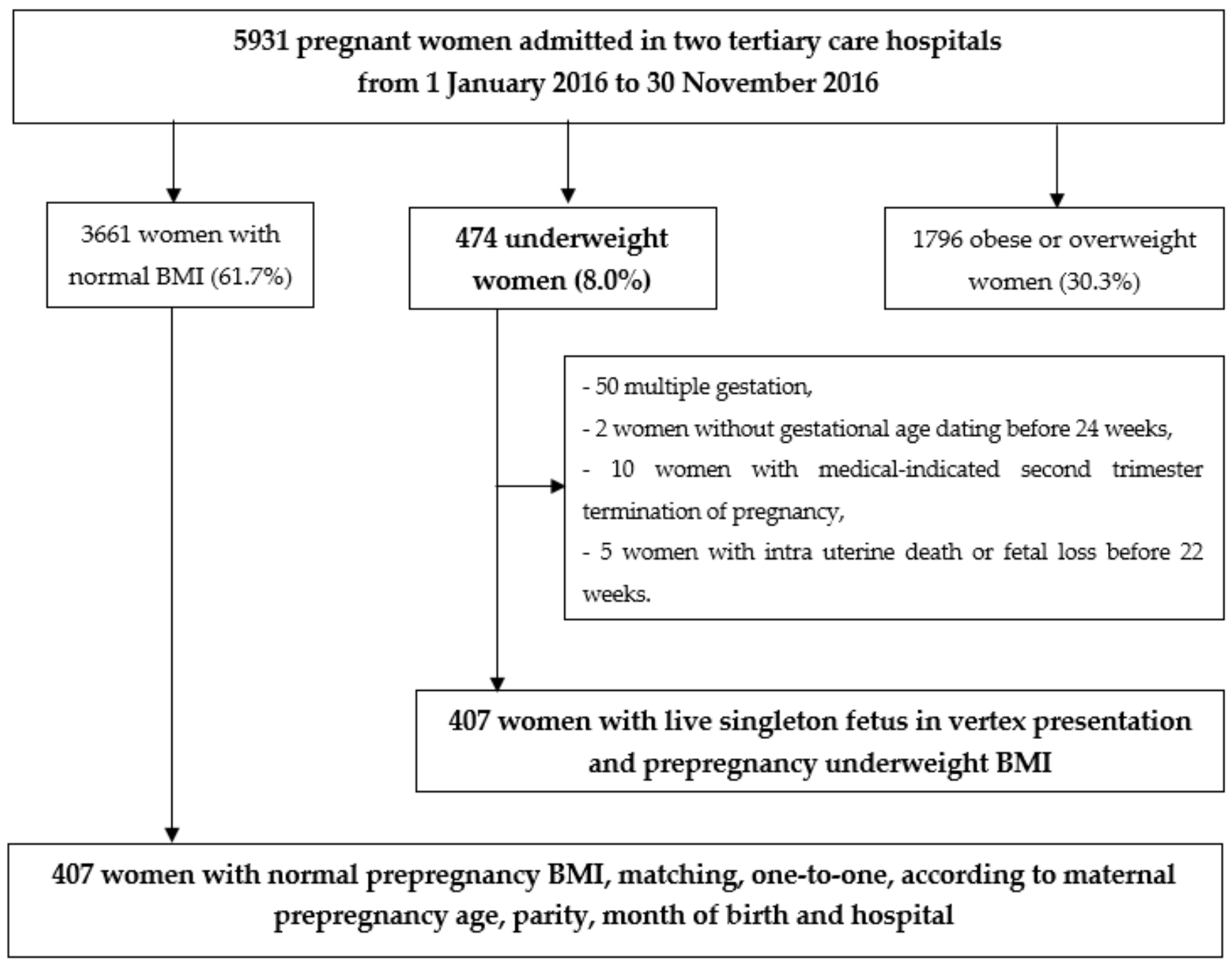

Figure 1. Study population. 
Table 1. Maternal and labour characteristics and maternal and neonatal outcomes according to the prepregnancy BMI.

\begin{tabular}{|c|c|c|c|}
\hline & $\begin{array}{c}\text { Underweight BMI } \\
\begin{array}{c}\left(<18.5 \mathrm{~kg} / \mathrm{m}^{2}\right) \\
n=407\end{array}\end{array}$ & $\begin{array}{c}\text { Normal BMI } \\
\left(18.5-24.9 \mathrm{~kg} / \mathrm{m}^{2}\right) \\
n=407\end{array}$ & $p$-Value \\
\hline \multicolumn{4}{|l|}{ Maternal characteristics } \\
\hline \multicolumn{4}{|l|}{ Maternal age (years) } \\
\hline Less than 20 years & $18(4.4)$ & $18(4.4)$ & - \\
\hline Between 20 and 39 years & $376(92.4)$ & $376(92.4)$ & - \\
\hline Over 39 years & $13(3.2)$ & $13(3.2)$ & - \\
\hline BMI before pregnancy $\left(\mathrm{kg} / \mathrm{m}^{2}\right)$ & $17.5 \pm 0.9$ & $21.5 \pm 1.8$ & $<0.001$ \\
\hline Nulliparity & $165(40.5)$ & $165(40.5)$ & - \\
\hline \multicolumn{4}{|l|}{ Geographic origin } \\
\hline Caucasian & $376(92.4)$ & $366(89.9)$ & 0.22 \\
\hline North Africa & $11(2.7)$ & $15(3.7)$ & 0.43 \\
\hline Sub-Saharan Africa & $11(2.7)$ & $11(2.7)$ & $>0.99$ \\
\hline Asian & $6(1.5)$ & $9(2.2)$ & 0.45 \\
\hline Overseas Departments & $3(0.7)$ & $6(1.5)$ & 0.34 \\
\hline Hispanic & 0 & 0 & - \\
\hline Smoking & $122(30.0)$ & $81(19.9)$ & 0.001 \\
\hline Previous caesarean delivery & $44(10.8)$ & $31(7.6)$ & 0.12 \\
\hline Previous hypertension & $3(0.7)$ & 0 & 0.25 \\
\hline Pregestational diabetes mellitus & $3(0.7)$ & $5(1.2)$ & 0.22 \\
\hline History of depression & $28(6.9)$ & $12(3.0)$ & 0.01 \\
\hline History of eating behaviour disorder & $25(6.1)$ & $10(2.5)$ & 0.01 \\
\hline ART-conceived pregnancy & $26(6.4)$ & $24(5.9)$ & 0.77 \\
\hline Gestational weight gain $(\mathrm{kg})$ & $13.1 \pm 4.2$ & $12.3 \pm 4.7$ & 0.02 \\
\hline Inadequate gestational weight gain & $179(46.4)$ & $174(44.7)$ & 0.65 \\
\hline Gestational diabetes mellitus & $29(7.1)$ & $25(6.1)$ & 0.57 \\
\hline Intrahepatic cholestasis of pregnancy & $2(0.5)$ & $9(2.2)$ & 0.03 \\
\hline Anaemia & $198(48.8)$ & $190(47.2)$ & 0.64 \\
\hline Threatened preterm labour & $35(8.6)$ & $15(3.7)$ & $<0.01$ \\
\hline Pregnancy-associated hypertensive disorders & $4(1.0)$ & $6(1.5)$ & 0.52 \\
\hline Antenatal suspicion of SGA * & $13(3.2)$ & $5(1.2)$ & 0.06 \\
\hline \multicolumn{4}{|l|}{ Labour characteristics } \\
\hline Gestational age at delivery (w) & $39.2 \pm 2.2$ & $39.6 \pm 1.7$ & 0.001 \\
\hline Preterm birth & $41(10.1)$ & $23(5.7)$ & 0.02 \\
\hline Less than 28 weeks & $2(0.5)$ & $1(0.3)$ & \\
\hline 28 to less than 32 & $5(1.2)$ & $2(0.5)$ & \\
\hline 32 to less than 36 & $34(8.4)$ & $20(4.9)$ & \\
\hline Iatrogenic preterm birth & $17(4.2)$ & $6(1.5)$ & 0.02 \\
\hline Planned caesarean delivery & $22(5.4)$ & $19(4.7)$ & 0.64 \\
\hline Induced labour & $65(16.0)$ & $78(19.2)$ & 0.23 \\
\hline Spontaneous vaginal delivery & $316(77.6)$ & 309 (75.9) & 0.56 \\
\hline Operative vaginal delivery & $47(11.6)$ & $51(12.5)$ & 0.67 \\
\hline Caesarean section during labour & $44(10.8)$ & 47 (11.6) & 0.74 \\
\hline \multicolumn{4}{|l|}{ Maternal outcome } \\
\hline 3rd or 4 th-degree perineal lacerations & $4(1.1)$ & $3(0.8)$ & 0.53 \\
\hline Postpartum haemorrhage (PPH) & $30(7.6)$ & $33(8.2)$ & 0.50 \\
\hline Severe PPH (blood loss > $1000 \mathrm{~mL}$ ) & $12(3.1)$ & $16(4.0)$ & 0.47 \\
\hline \multicolumn{4}{|l|}{ Neonatal outcome } \\
\hline Birth weight $(\mathrm{g})$ & $3055 \pm 580$ & $3281 \pm 511$ & $<0.001$ \\
\hline Birth weight (centile) & $35 \pm 27$ & $46 \pm 27$ & $<0.001$ \\
\hline Birth weight Z-score & $-0.2 \pm 1.0$ & $0.14 \pm 1.0$ & $<0.001$ \\
\hline $\mathrm{SGA}^{+}$ & $93(22.9)$ & $45(11.1)$ & $<0.001$ \\
\hline Birth weight $2500 \mathrm{~g}$ or less & $58(14.3)$ & $24(5.9)$ & 0.001 \\
\hline LGA $\ddagger$ & $9(2.2)$ & $26(6.4)$ & $<0.01$ \\
\hline Birth weight $4000 \mathrm{~g}$ or more & $13(3.2)$ & $27(6.6)$ & 0.02 \\
\hline 5-min Apgar score less than 7 & $5(1.2)$ & $3(0.7)$ & 0.73 \\
\hline $\mathrm{pH}<7.10$ & $8(2.0)$ & $20(5.3)$ & 0.02 \\
\hline
\end{tabular}


Table 1. Cont.

\begin{tabular}{|c|c|c|c|}
\hline & $\begin{array}{c}\text { Underweight BMI } \\
\begin{array}{c}\left(<18.5 \mathrm{~kg} / \mathrm{m}^{2}\right) \\
n=407\end{array}\end{array}$ & $\begin{array}{c}\text { Normal BMI } \\
\left(18.5-24.9 \mathrm{~kg} / \mathrm{m}^{2}\right) \\
n=407\end{array}$ & $p$-Value \\
\hline Transfer to NICU & $53(13.0)$ & $44(10.8)$ & 0.33 \\
\hline NICU hospitalization longer than $24 \mathrm{~h}$ & $26(6.4)$ & $21(5.2)$ & 0.45 \\
\hline Respiratory distress syndrome & $29(7.1)$ & $33(8.1)$ & 0.60 \\
\hline Neonatal hyperbilirubinemia & $17(4.2)$ & $6(1.5)$ & 0.02 \\
\hline Neonatal hypoglycaemia & $7(1.7)$ & $3(0.7)$ & 0.20 \\
\hline Intraventricular haemorrhage greater than grade 2 & 0 & $3(0.7)$ & 0.25 \\
\hline Need for resuscitation or intubation & $3(0.7)$ & $2(0.5)$ & 0.98 \\
\hline Sepsis & $4(1.0)$ & $5(1.2)$ & 0.96 \\
\hline Seizures & 0 & $1(0.3)$ & 0.87 \\
\hline Neonatal death & $1(0.3)$ & $3(0.7)$ & 0.62 \\
\hline
\end{tabular}

ART, assisted reproductive technologies; SGA: small-for-gestational age; LGA: large-for-gestational-age; NICU, neonatal intensive care unit. * Antenatal suspicion of SGA: ultrasonographic estimated foetal weight < 10th centile adjusting for gestational age and sex [14]. † SGA: birth weight $<10$ th centile adjusting for gestational age and the offspring's sex [21]. ‡ LGA: birth weight < 90th centile adjusting for gestational age and the offspring's sex [21]. Continuous data are expressed as means \pm standard deviations; discrete data are expressed as $n$ or $n(\%)$. Student $\mathrm{t}$ test, $\chi^{2}$ test, non-parametric Mann-Whitney test, and Fisher's exact test were used as appropriate. A $p$-value of 0.05 was considered significant.

Gestational age at delivery was significantly different, but not clinically meaningful, in both groups $(39.2 \pm 2.2$ in study group compared to $39.6 \pm 1.7$ weeks in control group, $p=0.001$ ), and the rates of overall PTB and iatrogenic PTB were higher in the study group ( $10.1 \%$ compared to $5.7 \%, p=0.02$; and $4.2 \%$ compared to $1.5 \%, p=0.02$, respectively) (Table 1). The groups differed according to smoking, inadequate GWG, and ICP (Table 2). More than half iatrogenic PTB (9/17) was due to antenatal suspicion of SGA in underweight women, compared to a third in the control group $(2 / 6)$.

Table 2. Univariate analysis of preterm birth among underweight and normal prepregnancy BMI women.

\begin{tabular}{|c|c|c|c|}
\hline & \multicolumn{2}{|c|}{ Preterm Birth * } & \multirow[b]{2}{*}{$p$} \\
\hline & No $(n=750)$ & Yes $(n=64)$ & \\
\hline Underweight women (BMI, $<18.5 \mathrm{~kg} / \mathrm{m}^{2}$ ) & $366(48.8)$ & $41(64.1)$ & 0.02 \\
\hline Categories of underweight women & & & 0.02 \\
\hline Severe thinness (BMI, $\left.<16 \mathrm{~kg} / \mathrm{m}^{2}\right)$ & $277(36.9)$ & $27(42.2)$ & \\
\hline Moderate thinness (BMI, $16-16.99 \mathrm{~kg} / \mathrm{m}^{2}$ ) & $69(9.2)$ & $9(14.1)$ & \\
\hline Mild thinness (BMI, $17-18.49 \mathrm{~kg} / \mathrm{m}^{2}$ ) & $20(2.7)$ & $5(7.8)$ & \\
\hline $\begin{array}{l}\text { Normal prepregnancy BMI women } \\
\left(\mathrm{BMI},>18 \mathrm{~kg} / \mathrm{m}^{2}\right)\end{array}$ & $384(51.2)$ & $23(36.0)$ & 0.02 \\
\hline Maternal age 40 years or greater & $25(3.3)$ & $1(1.6)$ & 0.45 \\
\hline Nulliparity & $302(40.3)$ & $28(43.8)$ & 0.59 \\
\hline Smoking & $173(23.1)$ & $30(46.9)$ & $<0.001$ \\
\hline ART-conceived pregnancy & $22(2.9)$ & $2(3.1)$ & 0.93 \\
\hline Inadequate GWG & $322(44.2)$ & $31(67.4)$ & $<0.01$ \\
\hline Pregnancy-associated hypertensive disorders & $13(1.8)$ & $3(4.7)$ & 0.15 \\
\hline $\begin{array}{l}\text { Threatened preterm labour required } \\
\text { hospitalization }\end{array}$ & $25(3.3)$ & $25(39.1)$ & $<0.001$ \\
\hline GDM & $45(6.0)$ & $9(14.1)$ & 0.02 \\
\hline Antenatal suspicion of SGA & $36(4.8)$ & $14(21.9)$ & $<0.001$ \\
\hline Anaemia & $360(48.3)$ & $28(44.4)$ & 0.56 \\
\hline $\mathrm{ICP}$ & $5(0.7)$ & $6(9.4)$ & $<0.001$ \\
\hline
\end{tabular}

BMI, body mass index; ART, assisted reproductive technology; GWG, gestational weight gain; GDM, gestational diabetes mellitus; ICP, intrahepatic cholestasis of pregnancy. Data are mean \pm standard deviation or $n(\%)$ unless otherwise specified. $\chi^{2}$ test and Fisher's exact test were used as appropriate. A $p$ value of 0.05 was considered significant. * Preterm birth was defined as delivery less than 37 completed weeks of gestation. 
In the multivariable logistic regression analysis adjusted for potential confounders (maternal age, parity, smoking, inadequate GWG, ICP, GDM, pregnancy-associated hypertensive disorders, and antenatal suspicion of SGA), maternal prepregnancy underweight (compared with normal) BMI was significantly associated with PTB (adjusted odds ratio (aOR) 2.32, 95\% confidence interval (CI) 1.12-4.81; $p=0.02$ ) (Table 3).

Table 3. Multivariate analysis of preterm birth among underweight and normal prepregnancy BMI women.

\begin{tabular}{ccc}
\hline & \multicolumn{2}{c}{$\begin{array}{c}\text { Preterm Birth } \\
(\boldsymbol{n}=\mathbf{6 4})\end{array}$} \\
Variable * & \multicolumn{1}{c}{\begin{tabular}{c} 
\\
\cline { 2 - 3 }
\end{tabular}} & $\begin{array}{c}\text { Adjusted OR (95\% CI) * } \\
\text {-Value }\end{array}$ \\
\hline Underweight women (BMI less than $\left.18.5 \mathrm{~kg} / \mathrm{m}^{2}\right)$ & $2.32(1.12-4.81)$ & 0.02 \\
Maternal age 40 years or greater & $0.40(0.04-3.48)$ & 0.06 \\
Nulliparity & $1.78(0.87-3.61)$ & 0.11 \\
Smoking & $3.01(1.45-6.25)$ & 0.01 \\
Inadequate GWG & $4.48(2.04-9.82)$ & 0.001 \\
Pregnancy-associated hypertensive disorders & $7.26(0.71-74.42)$ & 0.09 \\
GDM & $2.00(0.72-5.60)$ & 0.19 \\
Antenatal suspicion of SGA & $36.44(8.95-148.30)$ & $<0.001$ \\
ICP & $28.46(5.91-137.13)$ & $<0.001$ \\
\hline
\end{tabular}

OR, odds ratio; CI, confidence interval; BMI, body mass index; GWG, gestational weight gain; GDM, gestational diabetes mellitus; ICP, intrahepatic cholestasis of pregnancy. ${ }^{*}$ Adjusted for maternal age, parity, inadequate GWG, ICP, GDM, pregnancy-associated hypertensive disorders, and antenatal suspicion of SGA.

Smoking (aOR 3.01, 95\% CI 1.45-6.25), inadequate GWG (aOR 4.48, 95\% CI 2.04-9.82), antenatal suspicion of SGA (adjusted OR 36.44, 95\% CI 8.95-148.30), and ICP (aOR 28.46, 95\% CI 5.91-137.13) were also significantly associated with PTB (Table 3).

Increasing rate of PTB was observed with accordance to increasing severity of underweight ( $7.8 \%$ in mild, $14.1 \%$ in moderate and $42.2 \%$ in severe underweight) (Table 2$)$. Maternal severe thinness $\left(B M I<16 \mathrm{~kg} / \mathrm{m}^{2}\right.$ ) (compared with mild thinness (BMI, $\left.17-18.49 \mathrm{~kg} / \mathrm{m}^{2}\right)$ ) was significantly associated with PTB (aOR 2.33, 95\% CI 1.18-19.35) in the multivariable logistic regression analysis adjusted for potential confounders (Table 3 ).

Birth weight ( $3055 \pm 580$ compared to $3280 \pm 511 \mathrm{~g}, p<0.001$ ) and birth weight Z-score $(-0.2 \pm 1.0$ compared to $0.14 \pm 1.0, p<0.001)$ were significantly lower for the newborns of those in the maternal underweight compared with the control women. The proportions of SGA and LBW neonates were significantly higher for the study group than the control group ( $22.9 \%$ compared to $11.1 \%, p<0.001$, and $14.3 \%$ compared to $5.9 \%, p<0.001)$. Immediate neonatal morbidity was similar in both groups (Table 1). The groups differed according to maternal age, smoking, history of depression, history of eating behaviour disorders, inadequate GWG, GDM and pregnancy-associated hypertensive disorders (Table 4).

Table 4. Univariate analysis of SGA neonates among underweight and normal prepregnancy BMI women.

\begin{tabular}{|c|c|c|c|}
\hline & \multicolumn{2}{|c|}{ SGA Neonates * } & \multirow[b]{2}{*}{$p$} \\
\hline & No $(n=676)$ & Yes $(n=138)$ & \\
\hline Underweight women (BMI, $<18.5$ kg $/ \mathrm{m}^{2}$ ) & $314(46.5)$ & $93(67.4)$ & $<0.001$ \\
\hline Categories of underweight women & & & $<0.0001$ \\
\hline Severe thinness $\left(\mathrm{BMI},<16 \mathrm{~kg} / \mathrm{m}^{2}\right)$ & $16(2.4)$ & $9(6.5)$ & \\
\hline Moderate thinness (BMI, $16-16.99 \mathrm{~kg} / \mathrm{m}^{2}$ ) & $56(8.3)$ & $22(15.9)$ & \\
\hline Mild thinness (BMI, $17-18.49 \mathrm{~kg} / \mathrm{m}^{2}$ ) & $242(35.8)$ & $62(44.9)$ & \\
\hline Normal prepregnancy BMI women (BMI, $>18 \mathrm{~kg} / \mathrm{m}^{2}$ ) & $362(53.5)$ & $45(32.6)$ & $<0.001$ \\
\hline Maternal age 40 years or greater & $19(2.8)$ & $7(5.1)$ & 0.17 \\
\hline Nulliparity & $266(39.4)$ & $64(46.4)$ & 0.13 \\
\hline Smoking & $145(21.5)$ & $58(42.0)$ & $<0.001$ \\
\hline
\end{tabular}


Table 4. Cont.

\begin{tabular}{|c|c|c|c|}
\hline & \multicolumn{2}{|c|}{ SGA Neonates * } & \multirow[b]{2}{*}{$p$} \\
\hline & No $(n=676)$ & Yes $(n=138)$ & \\
\hline History of eating behavior disorders & $24(3.6)$ & $11(8.0)$ & 0.02 \\
\hline History of depression & $25(3.7)$ & $15(10.9)$ & $<0.001$ \\
\hline ART-conceived pregnancy & $41(6.1)$ & $9(6.5)$ & 0.84 \\
\hline Inadequate GWG & $274(42.7)$ & $79(59.4)$ & $<0.001$ \\
\hline Pregnancy-associated hypertensive disorders & $7(1.0)$ & $3(2.2)$ & 0.28 \\
\hline GDM & $48(7.1)$ & $6(4.4)$ & 0.24 \\
\hline Anaemia & $331(49.3)$ & $57(41.6)$ & 0.10 \\
\hline ICP & $11(1.6)$ & 0 & 0.99 \\
\hline
\end{tabular}

BMI, body mass index; ART, assisted reproductive technology; GWG, gestational weight gain; GDM, gestational diabetes mellitus; ICP, intrahepatic cholestasis of pregnancy. Data are mean \pm standard deviation or $n(\%)$ unless otherwise specified. $\chi 2$ test and Fisher's exact test were used as appropriate. A $p$ value of 0.05 was considered significant. * SGA was defined as birth weight less than the 10 th percentile adjusting for gestational age and the offspring's sex [21].

In the multivariable logistic regression analysis adjusted for potential confounders, only maternal underweight BMI was significantly associated with SGA (aOR 2.38, 95\% CI 1.58-3.58; $p<0.001)$.

\section{Discussion}

This study reports a retrospective case-control analysis of women who prepregnancy BMI was underweight (study group) or normal (control group by matching age and parity), and PTB and SGA according to prepregnancy BMI. We found that maternal prepregnancy underweight BMI was associated with higher rates of PTB and SGA than normal BMI. Increasing rate of PTB was observed in accordance with increasing severity of underweight BMI.

Our data are robust. We included women who gave birth at two tertiary care hospitals that are in the same perinatal network with common guidelines concerning pregnancy and delivery management. We included women with normal BMI who were matched for the major factors known to affect pregnancy outcomes (maternal age and parity). All neonates were also routinely examined by a qualified neonatologist after delivery. Moreover, history of eating behaviour disorder and history of depression, that are wellknown to be associated with PTB and SGA in underweight women, were systematically sought in medical files [26,27].

Our results must be interpreted in light of certain limitations. First, the main limitation of this study is the retrospective design which is a source of bias inherent to such investigations. Prepregnancy BMI was based on height and the first weight noted in the obstetric record. This first weight noted in the electronic medical record database of the two hospitals corresponded to the statements of the woman at the first exam during pregnancy that may represent a memory bias. Nevertheless, some of these women were seen in hospitals before pregnancy, and prepregnancy weight was well-notified in the electronic record. Second, although the sample size of this retrospective case-control study was large $(n=814)$, our study may lack sufficient statistical power to detect small but clinically relevant differences in infrequent perinatal outcomes. Moreover, women in the control group were matched by the major factors known to affect pregnancy outcomes (maternal age and parity); however, we could not exclude the possibility that additional hidden confounders that were unfortunately not recorded (ie, socio-economic status, level of education, and haemoglobin level at the beginning of the pregnancy) could explain the differences observed between groups and may represent reported bias for rates of PTB and SGA [28,29]. We also considered that using matching, one-to-one, according to month of birth and hospital especially avoided significant variation regarding diagnosis of PTB and SGA, and need for obstetric intervention. These limitations notwithstanding, our study supports the continued close multidisciplinary follow-up of underweight women during pregnancy to prevent PTB and SGA with regular evaluation of cervix status and 
uterine contractions and regular ultrasound fetal growth monitoring during third trimester. Identifying these specific high-risk pregnant women is pragmatic and practical for all physicians, this information could be used for prepregnancy counselling in these women with low BMI, and physicians should be aware of perinatal outcome among underweight women.

Rates of underweight pregnant women $(6.9 \%)$, overall PTB $(10.1 \%)$ and medically induced PTB (4.2\%) were observed in accordance with previous publications [2,4,30]. Several studies have evaluated the association between maternal underweight BMI and PTB [3-6,31]. The largest meta-analysis, involving 78 studies and 1,025,794 women, reported that prepregnancy underweight was significantly associated with PTB, compared to a normal prepregnancy BMI (adjusted relative risk (RR) 1.29, 95\% CI 1.15-1.46) [6]. However, this meta-analysis included a potential major bias inherent in combining studies from developed and developing countries [6]. Our results are consistent with other wellestablished findings in the literature: increasing severity of prepregnancy underweight BMI was associated with increasing risk-adjusted PTB $[3,24,30]$, maternal underweight BMI was also associated with moderate PTB (between 32 and 36 weeks) rather than with severe PTB (less than 28 weeks) [30,31], and iatrogenic PTB was higher among underweight women [4]. In agreement with the literature [6,23-25,32], our study also showed that more than half iatrogenic PTB $(9 / 17)$ was due to antenatal suspicion of SGA in underweight women, compared to a third in the control group. Despite the small sample size of the study, antenatal suspicion of altered fetal growth seems to be an important risk factor for PTB.

\section{Conclusions}

Our study showed that women's prepregnancy underweight, compared to women with normal BMI, was associated with an increase in PTB and in SGA neonates in singleton pregnancies. This study might be useful for prepregnancy counselling in women with low BMI who are willing to get pregnant.

Author Contributions: Conceptualization, E.L. and G.D.; formal analysis, E.L. and G.D.; investigation, E.L., E.M., M.B. and N.W.; methodology, E.L., A.L.T. and G.D.; software, A.L.T.; writing—original draft, E.L., M.B. and G.D.; writing —review and editing, G.D. All authors have read and agreed to the published version of the manuscript.

Funding: The authors received no external funding.

Institutional Review Board Statement: This present study was conducted in accordance with the French approved guidelines. All participants received written information. Written consent was not required for retrospective study according to the French law, but each woman got the opportunity to opt out of the analysis. The study protocol was approved by a Research Ethics Committee (Groupe Nantais d'Ethique dans le Domaine de la Santé (GNED)) on 27 June 2017 before the beginning of the study.

Informed Consent Statement: Informed consent was obtained from all subjects involved in the study.

Data Availability Statement: The data presented in this study are available on request from the corresponding author. The data are not publicly available due to institutional policy.

Conflicts of Interest: The authors declare no conflict of interest.

\section{References}

1. World Health Organization. International Classification of Adult Underweight, Overweight and Obesity According to BMI. Available online: http:/ / www.assesmentpsychology.com/icbmi.htm (accessed on 8 November 2019).

2. Blondel, B.; Pierrat, V.; Foix-L'Hélias, L. Changes in conditions at birth in France from 1995 to 2016: Results of the National Perinatal Surveys. Arch. Pédiatr. 2018, 25, 245-246. [CrossRef] [PubMed]

3. Girsen, A.I.; Mayo, J.A.; Carmichael, S.L.; Phibbs, C.S.; Shachar, B.Z.; Stevenson, D.K.; Lyell, D.J.; Shaw, G.M.; Gould, J.B. Women's prepregnancy underweight as a risk factor for preterm birth: A retrospective study. BJOG Int. J. Obstet. Gynaecol. 2016, 123, 2001-2007. [CrossRef] [PubMed] 
4. Shaw, G.M.; Wise, P.H.; Mayo, J.; Carmichael, S.L.; Ley, C.; Lyell, D.J.; Shachar, B.Z.; Melsop, K.; Phibbs, C.S.; Stevenson, D.K.; et al. Maternal Prepregnancy Body Mass Index and Risk of Spontaneous Preterm Birth. Paediatr. Périnat. Epidemiol. 2014, 28, 302-311. [CrossRef] [PubMed]

5. Lynch, A.M.; Hart, J.E.; Agwu, O.C.; Fisher, B.M.; West, N.A.; Gibbs, R.S. Association of extremes of prepregnancy BMI with the clinical presentations of preterm birth. Am. J. Obstet. Gynecol. 2014, 210, 428.e1-428.e9. [CrossRef]

6. Han, Z.; Mulla, S.; Beyene, J.; Liao, G.; McDonald, S.D. Maternal underweight and the risk of preterm birth and low birth weight: A systematic review and meta-analyses. Int. J. Epidemiol. 2010, 40, 65-101. [CrossRef] [PubMed]

7. ESH/ESC. Practice guidelines for the management of arterial hypertension of the European Society of Hypertension (ESH) and the European Society of Cardiology (ESC): ESH/ESC Task Force for the Management of Arterial Hypertension. J. Hypertens. 2013, 31, 1925-1938. [CrossRef] [PubMed]

8. Institute of Medicine and National Research Council, Committee to Reexamine IOM Pregnancy Weight Guidelines. Weight Gain During Pregnancy: Reexamining the Guidelines; Rasmussen, K.M., Yaktine, A.L., Eds.; National Academies Press: Washington, DC, USA, 2009.

9. Goonewardene, M.; Shehata, M.; Hamad, A. Anaemia in pregnancy. Best Pract. Res. Clin. Obstet. Gynaecol. 2012, 26, 3-24. [CrossRef] [PubMed]

10. International Association of Diabetes Pregnancy Study Groups. Recommendations on the diagnosis and classification of hyperglycaemia in pregnancy. Diabetes Care 2010, 33, 676-682. [CrossRef] [PubMed]

11. Collège national des gynécologues et obstétriciens français; Société francophone du diabète. Gestational diabetes. J. Gynecol. Obstet. Biol. Reprod. 2010, 39, S338-S342.

12. American College of Obstetricians and Gynecologists; Task Force on Hypertension in Pregnancy. Hypertension in pregnancy. Report of the American College of Obstetricians and Gynecologists' Task Force on Hypertension in Pregnancy. Obstet. Gynecol. 2013, 122, 1122-1131.

13. Ego, A. Definitions: Small for gestational age and intrauterine growth retardation. J. Gynecol. Obstet. Biol. Reprod. 2013, 42, 872-894. [CrossRef] [PubMed]

14. Vayssière, C.; Sentilhes, L.; Ego, A.; Bernard, C.; Cambourieu, D.; Flamant, C.; Gascoin, G.; Gaudineau, A.; Grangé, G.; HoufflinDebarge, V.; et al. Fetal growth restriction and intra-uterine growth restriction: Guidelines for clinical practice from the French College of Gynaecologists and Obstetricians. Eur. J. Obstet. Gynecol. Reprod. Biol. 2015, 193, 10-18. [CrossRef] [PubMed]

15. Vayssiere, C.; Haumonte, J.B.; Chantry, A.; Coatleven, F.; Debord, M.P.; Gomez, C.; Le Ray, C.; Lopez, E.; Salomon, L.J.; Senat, M.V.; et al. Prolonged and post-term pregnancies: Guidelines for clinical practice from the French College of Gynecologists and Obstetricians (CNGOF). Eur. J. Obstet. Gynecol. Reprod. Biol. 2013, 169, 10-16. [CrossRef]

16. Ducarme, G.; Pizzoferrato, A.; de Tayrac, R.; Schantz, C.; Thubert, T.; Le Ray, C.; Riethmuller, D.; Verspyck, E.; Gachon, B.; Pierre, F.; et al. Perineal prevention and protection in obstetrics: CNGOF clinical practice guidelines. J. Gynecol. Obstet. Hum. Reprod. 2019, 48, 455-460. [CrossRef]

17. Sentilhes, L.; Vayssière, C.; Deneux-Tharaux, C.; Aya, A.G.; Bayoumeu, F.; Bonnet, M.P.; Djoudi, R.; Dolley, P.; Dreyfus, M.; Ducroux-Schouwey, C.; et al. Postpartum hemorrhage: Guidelines for clinical practice from the French Society of Anesthesiology and Intensive Care (SFAR). Eur. J. Obstet. Gynecol. Reprod. Biol. 2016, 198, 12-21. [CrossRef] [PubMed]

18. Salomon, L.J.; Bernard, J.P.; De Stavola, B.; Kenward, M.; Ville, Y. Birth weight and size: Charts and equations. J. Gynecol. Obstet. Biol. Reprod. 2007, 36, 50-56. [CrossRef] [PubMed]

19. Mamelle, N.; Munoz, F.; Grandjean, H. Fetal growth from the AUDIPOG study. I. Establishment of reference curves. J. Gynecol. Obstet. Biol. Reprod. 1996, 25, 61-70.

20. Chabernaud, J.L. Neonatal resuscitation in delivery room: New advances. Arch. Pediatr. 2005, 12, 477-490. [CrossRef] [PubMed]

21. Adamkin, D.H. Nonatal hypoglycemia. Seminars Semin Fetal Neonatal Med. 2017, 22, 36-41. [CrossRef] [PubMed]

22. Murphy, D.J.; Liebling, R.E.; Verity, L.; Swingler, R.; Patel, R. Early maternal and neonatal morbidity associated with operative delivery in second stage of labour: A cohort study. Lancet 2001, 358, 1203-1207. [CrossRef]

23. Sebire, N.J.; Jolly, M.; Harris, J.; Regan, L.; Robinson, S. Is maternal underweight really a risk factor for adverse pregnancy outcome? A population-based study in London. Br. J. Obstet. Gynaecol. 2001, 108, 61-66.

24. Salihu, H.; Mbah, A.; Alio, A.; Clayton, H.; Lynch, O. Low pre-pregnancy body mass index and risk of medically indicated versus spontaneous preterm singleton birth. Eur. J. Obstet. Gynecol. Reprod. Biol. 2009, 144, 119-123. [CrossRef] [PubMed]

25. Rahman, M.M.; Abe, S.K.; Kanda, M.; Narita, S.; Rahman, S.; Bilano, V.; Ota, E.; Gilmour, S.; Shibuya, K. Maternal body mass index and risk of birth and maternal health outcomes in low- and middle-income countries: A systematic review and meta-analysis. Obes. Rev. 2015, 16, 758-770. [CrossRef] [PubMed]

26. Ante, Z.; Luu, T.M.; Mph, J.H.; He, S.; Taddeo, D.; Lo, E.; Auger, N. Pregnancy outcomes in women with anorexia nervosa. Int. J. Eat. Disord. 2020, 53, 673-682. [CrossRef] [PubMed]

27. Ghimire, U.; Papabathini, S.S.; Kawuki, J.; Obore, N.; Musa, T.H. Depression during pregnancy and the risk of low birth weight, preterm birth and intrauterine growth restriction- an updated meta-analysis. Early Hum. Dev. 2021, 152, 105243. [CrossRef]

28. Margerison, C.E.; Luo, Z.; Li, Y. Economic conditions during pregnancy and preterm birth: A maternal fixed-effects analysis. Paediatr. Périnat. Epidemiol. 2019, 33, 154-161. [CrossRef] [PubMed]

29. Ray, J.G.; Berger, H.; Park, A.L. Population-based study of serum ferritin in early pregnancy and adverse perinatal outcomes. Paediatr. Perinat. Epidemiol. 2020, 34, 706-712. [CrossRef] 
30. Salmon, C.; Thibon, P.; Prime, L.; Renouf, S.; Dreyfus, M.; Dolley, P. Impact of maternal underweight on obstetric and neonatal prognosis: A retrospective study. Eur. J. Obstet. Gynecol. Reprod. Biol. 2021, 260, 6-9. [CrossRef] [PubMed]

31. Ancel, P.-Y.; Saurel-Cubizolles, M.-J.; Di Renzo, G.C.; Papiernik, E.; Breart, G. A complete list of members of the Europop Group may be found on page 1169 Very and moderate preterm births: Are the risk factors different? BJOG Int. J. Obstet. Gynaecol. 1999, 106, 1162-1170. [CrossRef] [PubMed]

32. Doherty, D.; Magann, E.; Francis, J.; Morrison, J.; Newnham, J. Pre-pregnancy body mass index and pregnancy outcomes. Int. J. Gynecol. Obstet. 2006, 95, 242-247. [CrossRef] [PubMed] 